\title{
A REPRESENTAÇÃO SOCIAL DA VELHICE CONSTRUÍDA POR ESTUDANTES DE CIÊNCIA \& TECNOLOGIA DA UFCG: UMA ABORDAGEM PLURIMETODOLÓGICA
}

\author{
André Augusto Diniz Lira ${ }^{1}$ \\ Lais Santos Barbosa de Souza ${ }^{2}$ \\ Edwirde Luiz Silva Camêlo ${ }^{3}$
}

\begin{abstract}
Resumo: Este trabalho analisa a representação social da velhice construída por universitários de C\&T da UFCG. A pesquisa contou com 297 participantes (11,62\% do universo) e teve como instrumentos um questionário, uma Associação Livre de Palavras e um Procedimento de Classificações Múltiplas. Para análise foi utilizada a análise da estatística descritiva, a Classificação Hierárquica Descendente, a Nuvem de Palavras e o Escalonamento Multidimensional. A representação da velhice se estrutura por: a) ganhos cognitivos; b) benefícios e vínculos familiares e c) perdas. Destacam-se os aspectos mais positivos da velhice, refletindo o envelhecimento bem-sucedido e o próprio lugar social dos participantes da pesquisa.
\end{abstract}

Palavras-chave: Velhice. Estudantes universitários. Representações sociais. Estudantes de Ciência \& Tecnologia.

\section{THE SOCIAL REPRESENTATION OF OLD AGE CONSTRUCTED BY STUDENTS OF SCIENCE \& TECHNOLOGY OF UFCG: A PLURIMETODOLOGICAL APPROACH}

\begin{abstract}
This paper analyzes the social representation of old age constructed by UFCG S\&T students. The survey consisted of 297 participants (11.62\% of the universe) and had as instruments a questionnaire, a Free Word Association and a Multiple Classification Procedure. For analysis, we used the analysis of descriptive statistics, the Descending Hierarchical Classification, the Word Cloud and the Multidimensional Scheduling. The representation of old age is structured by: a) cognitive gains; b) family benefits and ties and c) losses. The most positive aspects of old age are highlighted, reflecting the successful aging and the social place of the research participants.
\end{abstract}

Keywords: Old age. University students. Social representations. Students of Science \& Technology.

\footnotetext{
${ }^{1}$ Professor do Programa da Pós-graduação em Educação da Universidade Federal de Campina Grande UFCG. Estágio Pós-doutoral em Linguística na UFRN. Estágio Pós-doutoral em Educação no Centro Internacional de Estudos em Representações Sociais e Subjetividade-Educação da Fundação Carlos Chagas (em andamento). Doutor em Educação pela UFRN. Líder do grupo de pesquisa Sociedade, Cultura e Educação.

${ }^{2}$ Psicóloga e Mestre em Educação pela UFCG.

${ }^{3}$ Professor do Departamento de Estatística (DE) na Universidade Estadual da Paraíba UEPB. Pós-doutorado em estatística aplicada à doenças epidemiológicas na Universidade de Granada. Doutor em Estatística e Investigación Operativa pela Universidade de Granada - Espanha, doutorado validado na UFMG.
} 


\section{INTRODUÇÃO}

O desenvolvimento da medicina e da tecnologia, os modelos de saúde pautados em sua promoção, o declínio da taxa de fecundidade e de natalidade, bem como o aumento da expectativa de vida populacional brasileira são fatores importantes para compreender o lugar que a temática da velhice ocupa no cenário brasileiro atual (CARVALHO; GARCIA, 2003; NERI, 2004; CAMPOLINA et al. 2013; NASCIMENTO; CALSA, 2017). Essa realidade contribuiu também para que os estudos sobre o envelhecimento ganhassem visibilidade, nos últimos anos, em perspectivas mais amplas para além da geriatria, como área da medicina, a favor da gerontologia, como área interdisciplinar, e de enfoques mais específicos como os de natureza psicossociológica (SANTOS; CARLOS, 2013; TURA; SILVA, 2012).

A visão que considera o envelhecimento a partir de um olhar multidimensional é recente. Por muito tempo, a velhice foi pensada pela ótica biológico-científica, destacando-se a atribuição de significados negativos, legitimando práticas e atitudes estereotipadas (NERI, 1991), que ainda perduram até os dias atuais.

Aproximadamente há uma década, começamos a desenvolver um projeto integrado de pesquisa tendo como sujeitos estudantes em vários níveis educacionais e em várias redes de ensino, de modo transversal, no intuito de comparar representações sociais em uma abordagem estrutural. Essa abordagem estrutural diferentemente da Teoria do Núcleo Central considera que uma representação social pode se estruturar a partir de um ou mesmo alguns núcleos de sentidos, seguindo uma trilha metodológica e interpretativa que pode ser melhor compreendida em trabalhos como os de Roazzi (1995), Braz et al. (2011) e nós próprios (LIRA, 2007) entre outros.

Parte dos nossos estudos (do projeto supracitado) foram publicados em trabalhos mais recentes em uma dimensão mais panorâmica dos dados (LIRA et al., 2016; LIRA, SOUZA, SILVA, 2017). As pesquisas desenvolvidas nos fizeram compreender a existência de uma mesma estrutura representacional em diferentes grupos investigados, compreendendo a velhice por seus a) ganhos cognitivos; b) benefícios e vínculos familiares e c) perdas. Nesta nova fase de análises, temos nos centrado em estudos específicos, testando hipóteses outrora levantadas, porque mesmo participando de uma mesma estrutura representacional há diferentes ênfases nos conteúdos representacionais que compõe essa estrutura. 


\section{REVISTA DE ADMINISTRAÇÃO EDUCACIONAL}

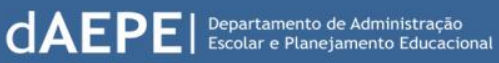

Em relação aos estudos com estudantes universitários consideramos importante fazer uma análise comparativa entre sujeitos de diversas áreas do conhecimento. Neste artigo, apresentamos especificamente os resultados que emergiram das análises da representação social de velhice produzida por estudantes da grande área de Ciência e Tecnologia da Universidade Federal de Campina Grande (UFCG). Nessa universidade os cursos dessa grande área estão distribuídos em três grandes Centros: o Centro de Ciências e Tecnologia (CCT), o Centro de Engenharia Elétrica e Informática (CEEI) e o Centro de Tecnologia e Recursos Naturais. O CCT foi desmembrado recentemente e do mesmo foram criados o CEEI e o CTRN. Esta pesquisa teve como sujeitos estudantes desses três grandes centros e não apenas os do CCT, como poderia ficar subentendido.

Uma das hipóteses iniciais que tínhamos era que os sujeitos dessa área poderiam representar a velhice de um modo mais negativo, uma vez que não participam de uma formação que enfoque essa temática nas suas trajetórias universitárias. Por outro lado, os cursos de Ciências Humanas e de Ciências da Saúde têm, em geral, nos últimos anos, incorporado discussões específicas sobre a problemática da velhice no cotidiano. Contudo, os resultados de C\&T nos fizeram compreender outra realidade. Os estudantes dessa grande área põem em relevo, em uma estruturação que é recorrente a todos os grupos investigados, interpretações mais positivas dessa fase de vida, inclusive com determinados sentidos que não se encontram nas outras áreas investigadas.

Como afirmamos, do ponto de vista teórico, esta pesquisa se pauta na teoria das representações sociais, que nos ajuda a compreender a dinamicidade, as mudanças em curso, a seleção de novos conteúdos e também a cristalização de sentidos historicamente pregnantes. Envelhecer, em nossa sociedade, desperta uma complexa rede de significados em um contexto histórico-cultural e social, que vivencia mudanças e reflete nos conceitos e paradigmas que também vão se modificando ao longo do tempo.

\section{METODOLOGIA}

De um universo de 2557 alunos matriculados, na grande área de C\&T, no CEEI, CTRN e CCT do Campus sede da UFCG, excetuando-se os estudantes que estavam no primeiro ano de vida universitária e também os estudantes de Matemática e Física (mais vinculados às 
denominadas Ciências Exatas e as Licenciaturas), participaram 297 sujeitos (11,62\% do universo). Esses anuíram com a pesquisa e responderam a um questionário. Para duas subamostras aplicou-se a Associação Livre de Palavras (251 sujeitos, 9,82\% do universo) e o Procedimento de Classificações Múltiplas (50 sujeitos, 1,96\% do universo).

Para a construção do banco de dados, como dito anteriormente, utilizamos o Questionário, a Associação Livre de Palavras (ALP) e o Procedimento de Classificações Múltiplas (PCM). As observações que fizemos por ocasião da coleta dos dados também nos ajudaram a compreender aspectos fundamentais da representação em tela, notadamente na aplicação da ALP e do PCM, que vieram a se constituir momentos singulares para comentários livres e explicações, que recuperamos por meio do diário de campo. Apesar de não termos lançado mão aqui desses registros ratificamos seu valor para nos iluminar na compreensão dos resultados como um todo.

O questionário era composto por uma ficha de caracterização (dados sócio-demográficos) e uma parte contendo questões relativas ao objeto de estudo, sendo apenas duas questões abertas e as outras objetivas, em sua maioria em escalas de tipo Likert. As questões objetivas do questionário foram analisadas pela estatística descritiva. As questões abertas, pelas técnicas da Análise Hierárquica Descendente e da Nuvem de Palavras. Utilizamos o software Iramuteq para análise desses dados. Como há material explicativo abundante em nosso meio sobre essas técnicas, inclusive um rico material instrucional, desenvolvido por Brígido Vizeu Camargo e Ana Maria Justo do Laboratório de Psicologia Social da Comunicação e Cognição - UFSC Brasil (CAMARGO; JUSTO, S/D), discutiremos adiante o PCM, ainda pouco utilizado no Brasil.

A $A L P$ foi aplicada com a palavra-estímulo velhice, sendo as respostas analisadas semanticamente e por meio das suas recorrências. Foram recolhidas 1196 palavras, das quais 706 palavras puderam ser agregadas em 17 categorias semânticas, tendo pelo menos sido evocadas 16 vezes (ver quadro 1 , nos resultados).

Com palavras mais recorrentes da ALP, realizamos o Procedimento de Classificações Múltiplas (PCM), que consiste em uma atividade de classificação proposta pelo pesquisador ao sujeito, que deverá agrupar uma série de itens [em nosso caso, cartões] por critérios próprios (classificação livre) ou apresentados pelo pesquisador (classificação dirigida). 


\section{REVISTA DE ADMINISTRAÇÃO EDUCACIONAL}

Em outras palavras, na classificação livre, foi solicitado aos participantes que formassem, segundo os seus próprios critérios, conjuntos com os cartões disponibilizados, onde estavam escritas as palavras mais representativas da velhice, segundo a visão deles próprios [proveniente da ALP], e também um cartão com a palavra velhice. Posteriormente, perguntávamos qual seriam os critérios para a formação de cada grupo. Nenhuma limitação foi imposta aos sujeitos quanto ao número de grupos a serem formados, nem quanto ao número de itens para cada grupo, nem ainda ao tempo da atividade necessária para realizar a classificação.

Para a classificação dirigida foi utilizada uma tabela com uma escala na qual deveriam julgar a pertinência de cada uma das palavras [dispostas em cartões] em conjuntos com a seguinte classificação: Não Associado; Pouco Associado; Mais ou Menos Associado; Muito Associado; Muitíssimo Associado.

O PCM possibilita a análise da estruturação do pensamento dos sujeitos através da regionalização dos pontos em mapas bi-dimensionais ou tri-dimensionais. Para esse artigo nos centramos mais na classificação livre do PCM. Para a classificação dirigida, discutiremos a média aritmética das médias dos elementos (palavras) segundo a escala utilizada.

A análise dos dados das classificações foi realizada através do Escalonamento Multidimensional (Multidimensional Scaling - MDS). O MDS é um tipo de análise multivariada que permite converter distâncias e similaridades de natureza psicológica em distâncias de tipo geométrica (distâncias euclidianas), na configuração de mapas perceptuais, bi ou tridimensionais (ROAZZI, 1995), nos quais as distâncias entre os pontos representam as variáveis estudadas e o relacionamento entre elas (SOUZA; SOUZA; SILVA, 2002).

\section{RESULTADOS}

\section{O perfil da amostra}

Antes de apresentar os resultados da análise da representação social da velhice, consideramos fundamental explicitar melhor o grupo investigado quanto a seu perfil social e sua relação com os idosos. 
Quanto à caracterização dos participantes, temos 56,90\% do sexo masculino e 43,10\% do sexo feminino. Isso demonstra que a preponderância do masculino, nesses cursos, historicamente vinculados às profissões tidas como masculinas, tem mudado o seu perfil, a considerar décadas anteriores. As engenharias têm recebido progressivamente uma maior quantidade de mulheres nas últimas décadas.

A maioria dos participantes são adeptos de religiões cristãs católica $(55,2 \%)$ ou evangélica $(19,5 \%)$ e 13,8\% definem-se como não religiosos. Em relação à renda familiar destacam-se as faixas com maior renda de 3 a 6 salários mínimos (SM) (33,4\%), de 6 a 10 SM (19,50\%) e de 10 SM acima (13,7\%). No total essas faixas equivalem a 66,6\% da amostra. Já as faixas com menor renda até $1 \mathrm{SM}(3,10 \%)$ e de 1 a 3 SM (30,4\%) perfazem 33,5\% da amostra. Essa estratificação é importante levar em consideração, porque a velhice não pode ser entendida como uma fase genérica e abstrata. Há diferentes formas de envelhecer, inclusive mediadas pelo lugar social dos sujeitos, como sinaliza a literatura atual.

Procuramos levantar qual o grau de envolvimento que os participantes da pesquisa têm com os idosos. É importante observar que, no conjunto, os resultados apontam para o envolvimento, pois 34,5\% responderam que seriam "muito" e 14,5\% seriam "muitíssimo" envolvidos; o que perfaz, um total de $49 \%$ das respostas. Os que figuram como "mais ou menos" envolvidos são $34,5 \%$. Apenas $2,4 \%$ se diz "não envolvido" e 14,2\% "pouco envolvidos".

Esse fato poderia sugerir que os sujeitos têm uma convivência com idosos mais próxima, mas essa não é a realidade, pois cerca de $70 \%$ afirmaram não conviver com idosos. Como a UFCG recebe uma quantidade significativa de estudantes que são de outras cidades e regiões do país, uma grande parte mora sozinho ou com colegas.

Por outro lado, a universidade, como ambiente formativo, oferece pouca oportunidade para essa convivência, pois $91,2 \%$ nunca participaram de projetos no âmbito institucional com idosos. Talvez o que explique melhor o grau de envolvimento seja a relação com o cuidado na história de vida dos sujeitos. Isso porque 58,8\% afirmaram que já cuidaram de um idoso ou mesmo ainda cuidam. Também 63,7\% afirmaram terem sido cuidados por idosos. Em ambos os casos, como veremos adiante, a família irá ocupar um lugar fundamental na representação social da velhice. 


\section{Representando a velhice}

Há uma lacuna de pesquisas utilizando a teoria das representações sociais tendo como sujeitos estudantes universitários de C\&T, sobretudo considerando a temática da velhice, que é bem mais estudada entre profissionais da saúde e de ciências humanas. Não encontramos em um amplo levantamento da literatura, na base de dados do Scielo e Google acadêmico, nenhuma pesquisa nesse sentido, apenas com outros referenciais analíticos. Essa pesquisa vem a contribuir para superar essa lacuna, tendo, portanto, uma dimensão exploratória, inclusive no que tange aos procedimentos de coleta de dados. Partindo dessa perspectiva, gostaríamos de sublinhar alguns elementos da condução da pesquisa com vistas a colaborar no desenvolvimento de pesquisas futuras com universitários da área de C\&T.

"Como você poderia caracterizar a velhice como uma fase de desenvolvimento humano?" Uma pergunta que, para nós, parecia de simples resolução não foi para uma grande parte dos participantes da pesquisa. Apenas 163 dos 297 participantes da pesquisa responderam as questões abertas [outra pergunta aberta remetia à expectativa de futuro que tinham de sua própria velhice, que não analisada neste artigo]. Alguns afirmaram que não saberiam responder, outros não diziam nada mais entregavam o questionário sem responder, atendo-se apenas as questões objetivas. Isso talvez decorra da própria dificuldade em colocar em palavras escritas o que pensavam, uma vez que quanto a outras técnicas utilizadas (ALP e PCM) não houve problemas nesse sentido; pelo contrário, houve grande engajamento e curiosidade. Surpreendemo-nos porque o mesmo questionário já tinha sido aplicado a alunos de nível educacional menor e a outros universitários, tendo a grande maioria respondido às perguntas abertas.

Apesar de uma grande quantidade de "não respostas" essas nos apontam tanto para a dificuldade de expressar por escrito o que pensavam quanto para certa expectativa de responder segundo algum critério ou conhecimento (científico) em nível universitário, que não o "senso comum". Ainda que o TCLE sublinhasse não haver respostas certas ou erradas, pois tratava-se de uma "pesquisa de opinião". E, por fim, não poderemos deixar de inferir também a 


\section{REVISTA DE ADMINISTRAÇÃO EDUCACIONAL}

possibilidade de um habitus mais prático e objetivo do desses estudantes de C\&T, que os fazia desconsiderar as perguntas subjetivas.

Não obstante, analisaremos as 163 respostas dos sujeitos que se dispuseram a responder e depois lançaremos mão da LAP e do PCM que possibilitou uma melhor abordagem de produção dos dados.

Para uma melhor compreensão dos dados da pergunta aberta, realizamos duas análises diferentes com os textos dos sujeitos por meio do Sofware Iramuteq. Na figura, a seguir, disponibilizamos a nuvem de palavras que foi construída a partir dos segmentos de textos analisados. Podemos observar que algumas palavras se destacaram na resposta como fase, vida, sabedoria, caracterizar, conhecimento, maturidade, adquirir. Isso pode ser verificado pelo tamanho maior das palavras que representam as mais importantes nas respostas formuladas.

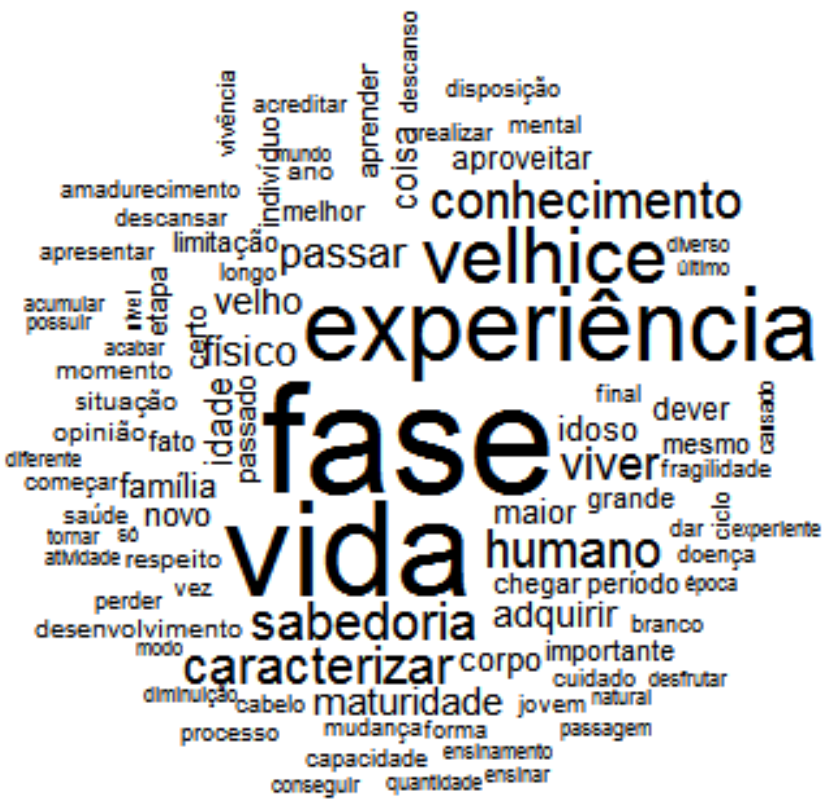

FIGURA 1: Nuvem de palavras: o que caracteriza a velhice?

Fonte: dados da pesquisa.

Se por um lado a nuvem de palavras nos permite verificar um conjunto geral de elementos inter-relacionados, por outro falta-nos uma melhor compreensão das relações que se podem estabelecer entre esses elementos. O que se pode inferir dessa Nuvem é uma ênfase em aspectos 


\section{REVISTA DE ADMINISTRAÇÃO EDUCACIONAL}

de caráter mais cognitivo. Essa ênfase se repetiria por meio de outra técnica ou conjunto de dados?

A análise hierárquica descendente especifica melhor por meio de classes de respostas as que são mais recorrentes. Nesse sentido, o conjunto das respostas podem ser tipificadas em 5 (cinco) classes (ver figura 2). As classes 1, 3, 5 evidenciam novamente os aspectos cognitivos da velhice. A classe 1 se articula em torno da aquisição de experiência, a classe 5 em torno da sabedoria e da maturidade, a classe 3 como uma fase de acúmulo de conhecimento. São nuanças diferentes de uma mesma faceta. Nas facetas 3 e 5 a dimensão social e da responsabilidade dos mais velhos para com o ensino das novas gerações é enfatizado.

A classe 4 é a que apresenta uma maior variabilidade de palavras e sentidos, ressaltandose a disposição, o aprender, o desenvolvimento. De todo modo, lembra ainda os aspectos cognitivos da velhice. A classe 2 se apresenta como a mais distinta das classes em termos de aproveitar a velhice, inserindo-se a família, a saúde, o descanso. O que se evidencia na análise hierárquica descendente é que se sobrepõem os aspectos cognitivos e, em segundo plano, se destaca a perspectiva de aproveitar a velhice, tendo como base o discurso sobre a família.
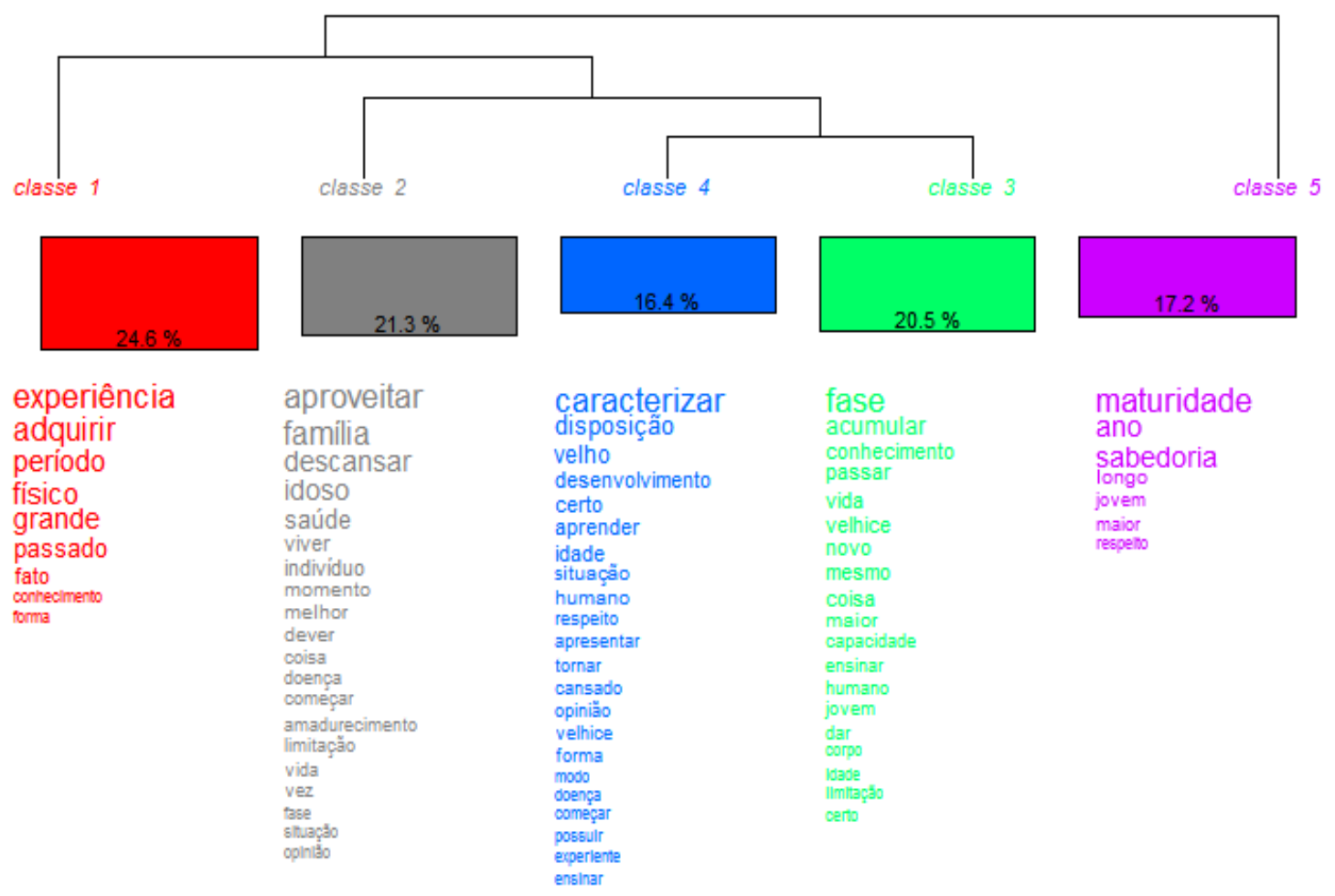

maturidade

ano

sabedoria

jovem

jovem

maioreno

conheciment
forma 


\section{REVISTA DE ADMINISTRAÇÃO EDUCACIONAL}

FIGURA 2: Análise Hierárquica descendente: o que caracteriza a velhice? Fonte: dados da pesquisa

O que se pode depreender, até então, é que quando se trata de uma resposta mais racionalizada como é o caso da escrita em um questionário, os participantes evocaram aspectos mais positivos da velhice sobressaltando a dimensão cognitiva e, ao mesmo tempo, apontando para um determinado tipo de velhice, a que pode aproveitar a vida. Seria uma particularidade desses sujeitos que responderam ao questionário? Será que outras técnicas poderiam iluminar o conhecimento da realidade?

Uma técnica que possibilita melhor a apreensão de conteúdos menos racionalizados é a Associação Livre de Palavras. Levantamos as palavras mais recorrentes para quase a totalidade dos participantes da pesquisa. As evocações livres podem ser verificadas no quadro abaixo. 
QUADRO 1: Associação Livre de Palavras com a palavra-estimulo velhice

\begin{tabular}{|c|c|c|c|c|c|}
\hline Categorias & $\mathbf{n}$ & $\%$ & Categorias & $\mathbf{n}$ & $\%$ \\
\hline Experiência & 82 & 6,86 & Cuidado & 30 & 2,51 \\
\hline Aposentadoria & 76 & 6,35 & Tranquilidade & 27 & 2,26 \\
\hline Família & 76 & 6,35 & Lazer & 21 & 1,76 \\
\hline Doenças & 69 & 5,77 & Rugas & 20 & 1,67 \\
\hline Sabedoria & 66 & 5,52 & Solidão & 18 & 1,51 \\
\hline Morte & 47 & 3,93 & Felicidade & 17 & 1,42 \\
\hline Saúde & 47 & 3,93 & Estabilidade & 17 & 1,42 \\
\hline Descanso & 44 & 3,68 & Maturidade & 16 & 1,34 \\
\hline Viagens & 33 & 2,76 & & & \\
\hline \multicolumn{4}{|c|}{ Total Parcial } & 706 & 59,03 \\
\hline \multicolumn{4}{|c|}{ Categorias com freq. $<16$} & 490 & 40,97 \\
\hline \multicolumn{4}{|c|}{ Total geral } & 1196 & 100 \\
\hline
\end{tabular}

Destaca-se, novamente, na tabela acima, que a maioria das palavras evocadas é de conteúdo mais positivo. Entre essas destacamos "Saúde”, "Descanso", "Viagens", "Tranquilidade", "Felicidade", "Lazer", "Estabilidade” e "Maturidade". Alguns pesquisadores defendem a necessidade de fazer uma análise em agrupamentos semânticos para melhor compreensão das palavras. Como a atividade realizada no PCM põe em movimento às classificações dos próprios sujeitos respeitando a sua lógica e construção discursiva, preferimos explicitar as classificações que emergiram.

A utilização da ALP tinha como finalidade levantar um conjunto de palavras que poderiam ser utilizadas como palavras-estímulo. Uma das vantagens dessa técnica é por os sujeitos frente aos estímulos que o seu grupo de pertença evocou para daí organizar e explicitar as razões que julga pertinentes quanto a organização dos grupos que viessem a construir.

A partir do estudo da regionalização dos pontos e da utilização da teoria das facetas é possível inferir que os principais agrupamentos indicam proximidade nos mapas e, por conseguinte, na interpretação do objeto em tela pelos sujeitos. A interpretação das facetas decorre da escuta atenta dos participantes da pesquisa a respeito das categorizações que processam quando estão em atividade de classificação. O mapa, a seguir, se organiza em três regiões de pontos bem demarcados no espaço bidimensional. A linha tracejada de pontos 


\section{REVISTA DE ADMINISTRAÇÃO EDUCACIONAL}

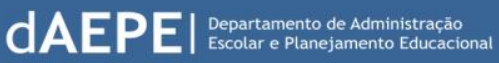

\section{ISSN 2359-82}

emergiu da nossa leitura interpretativa das facetas, em conjunto também com outras pesquisas já citadas anteriormente. Observa-se uma estrutura de três conjuntos de pontos regionalizados que denominamos de faceta ganhos cognitivos, faceta vínculos familiares e benefícios e faceta perdas.

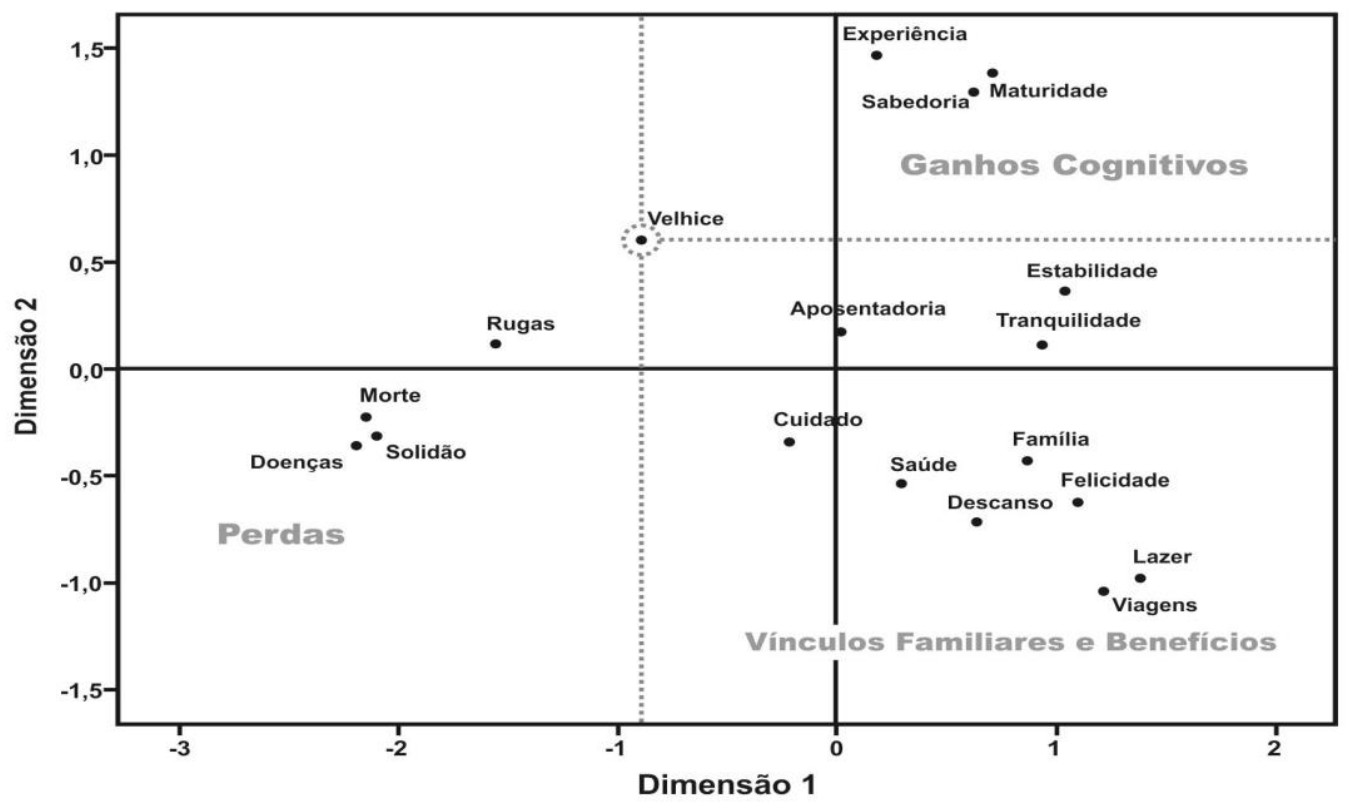

GRÁFICO 1: Resultado do Procedimento de Classificações Múltiplas (modalidade livre)

Um conjunto de elementos dispostos, na mesma região, associa a velhice aos ganhos cognitivos: a experiência, a maturidade, a sabedoria. Esses elementos juntamente com outros estão presentes no discurso dos sujeitos de outras áreas do conhecimento (LIRA, SOUZA, SILVA, 2017), sendo articuladores da faceta. Segundo Neri (2007), a caracterização de velhice vinculada à sabedoria pode ser considerada como um exemplo de preconceito positivo.

Em outra região do mapa, destacam-se os vínculos familiares e benefícios da velhice. É necessário, segundo os sujeitos, a família como uma instituição que pode proporcionar uma melhor qualidade de vida e promover benefícios como o cuidado e a saúde, sendo o lugar de segurança para o idoso. Apesar da ressalva dos mesmos que a família pode, eventualmente, ser uma instituição que negligência os direitos do idoso. No entanto, salientamos que, para esses sujeitos, a velhice está muito associada ao vínculo familiar. Podemos perceber inclusive, nos 


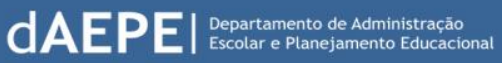

gráficos, que os elementos representacionais saúde, cuidado, família, descanso e felicidade aparecem juntos em uma mesma região do gráfico.

Ao estudar as representações sociais de felicidade entre idosos na zona urbana de Campinas-SP, Camargo et al. (2011, p. 247) apontaram que a felicidade na velhice se relaciona com o bem estar social e familiar [associada aos idosos com mais anos de estudo] e a saúde [associada ao Índice de Vulnerabilidade Social Médio]. Essa pesquisa corrobora com o quadro geral do que expomos aqui sobre a importância da família, da manutenção de bons vínculos afetivos e da saúde para o idoso, provavelmente como um conjunto de representações associadas.

Destacam-se ainda da faceta vínculos familiares e benefícios, em uma sub-região do gráfico, os elementos viagens e lazer e, em outra sub-região, os elementos aposentadoria, estabilidade e tranquilidade. Vale salientar que essas sub-regiões se encontram em uma mesma faceta, fazendo parte, portanto, de um mesmo conjunto interpretativo. A aposentadoria, por exemplo, no discurso dos sujeitos por ocasião do PCM, era apresentada como uma oportunidade para usufruto do dinheiro, para poder viajar e como a decorrência para a estabilidade financeira almejada.

Na faceta perdas se evidenciam os elementos: Morte, Doenças, Solidão e Rugas. Não obstante, a presença desses elementos vinculados às perdas, os aspectos mais positivos, no conjunto, são discursivamente mais valorizados, notadamente os da faceta ganhos cognitivos.

Realizamos, por fim, um PCM na modalidade dirigida com uma tabela em que cada palavraestímulo seria agrupada em grupos, através da seguinte escala: Não associado; Pouco associado; Mais ou menos associado; Muito Associado; Muitíssimo Associado. Para fins de análise e estatística consideramos a escala: 1 para Não Associado, 2 Pouco associado, 3 Mais ou Menos Associado, 4 Muito Associado e 5 para Muitíssimo Associado. Calculamos, então, a média das médias dos elementos, considerando-os nas facetas correspondentes acima descritas, encontradas na classificação dirigida.

As médias gerais das facetas corroboram, em parte, com as interpretações anteriores. A faceta ganhos cognitivos novamente se sobrepõe as demais atingindo uma média geral de 4,4, ou seja, seus elementos estariam compreendidos de muito a muitíssimo associados à velhice. As facetas vínculos familiares e benefícios apresenta um escore de 3,45 e a faceta perdas 3,49, ou 


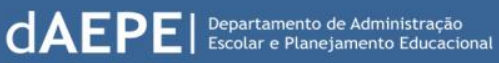

seja, praticamente iguais. Seus elementos estariam em uma faixa de Mais ou Menos à Muito Associados.

\section{DISCUSSÃO}

Neri (1991, p. 33), uma das autoras mais reconhecidas no estudo da velhice no Brasil, afirmou que não há uma única resposta sobre o que é ser velho em nosso país, visto que “[...] o próprio fenômeno da velhice tem múltiplos significados, contextualizados por fatores individuais, interindividuais, grupais e socioculturais." Apesar da ressalva a própria pesquisadora, ao longo de sua carreira, desenvolveu e orientou uma série de pesquisas sobre a velhice e o envelhecimento na ótica da sociedade, justamente em busca de uma compreensão mais contextual da mesma (entre esses se destacam: NERI (1991); NERI (2007). Nosso intuito tem sido o de procurar conhecer as regularidades e especificidades das representações sociais da velhice no afã de poder melhor intervir educacionalmente.

Ideias equivocadas em relação ao envelhecimento foram disseminadas por um período significativo em nossa sociedade, dentre elas a de que não existe desenvolvimento nesta fase. Araújo, Coutinho e Carvalho (2005, p. 120) relatam que essa perspectiva desafiou até a própria Psicologia do Envelhecimento, que precisou "conciliar os conceitos de desenvolvimento e envelhecimento, tradicionalmente tratados como antagônicos, tanto pelos cientistas quanto pela sociedade civil e a família" e considerar a velhice como uma fase onde há ganhos e conquistas, e uma importante fase do desenvolvimento humano, assim como a infância, a adolescência e a fase adulta.

Nas últimas décadas, muitas pesquisas evidenciaram o caráter ambivalente, no sentido de perdas e ganhos, nas representações sociais de envelhecimento entre todas as faixas etárias, desde a década de 90 (NERI, 1991; VELOZ; NASCIMENTO-SCHULZE; CAMARGO, 1999; ALMEIDA; CUNHA, 2003; MAGNABOSCO-MARTINS; VIZEU-CAMARGO; BIASUS, 2008; RECH WACHELK, et al., 2008; VIEIRA, et al., 2015; NASCIMENTO; CALSA, 2017).

Os resultados da pesquisa aqui apresentados se direcionam a uma especificidade que emerge de uma estrutura representacional que, em nossa hipótese, é compartilhada por outros grupos na sociedade (LIRA, 2017). Como a própria Neri (2007) destacou a velhice é concebida de formas distintas e é vivenciada também de formas distintas. Para os sujeitos da área de C\&T a velhice é compreendida tanto pela releitura proposta pela mídia diariamente quanto pelo lugar 


\section{REVISTA DE ADMINISTRAÇÃO EDUCACIONAL}

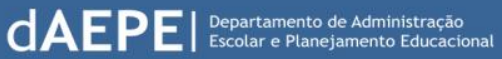

que ocupam na estrutura social, uma vez que possuem uma renda familiar diferenciada. Quando tratamos da mídia incluímos aqui os movimentos de tentativa de conscientização financiados pelos próprios governos visando à superação de leituras preconceituosas e negativas da velhice.

A velhice que os estudantes universitários de C\&T representam é, ainda, uma velhice bem-sucedida, que provavelmente vivenciam enquanto netos, sobrinhos, filhos etc. de uma classe privilegiada na hierarquia social. Nesse sentido, a representação da velhice tão distante deles do ponto de vista temporal é, de fato, um espelho de suas condições materiais de existência. Destacamos que era muito recorrente falas espontâneas que revelavam uma postura mais positiva sobre a velhice por ocasião da aplicação dos instrumentos de coleta de dados.

Neste cenário, a ideia de um envelhecimento bem-sucedido ganha força. Este modelo reconhece que é possível envelhecer com qualidade de vida, conquistando ganhos, para além das perdas esperadas nessa fase. Em consonância com essa perspectiva, Veloz, NascimentoSchulze e Camargo (1999, p.4) discorrem que esses modelos pautados em uma velhice bemsucedida entendem que "[...] apesar do envelhecimento continuar sendo representado na base de perdas, as pessoas idosas têm muitas capacidades de reserva que ficam sem ser exploradas, quer dizer, ganhos que passam desapercebidos e, em consequência, não são valorizados.”

\section{CONSIDERAÇÕES FINAIS}

Os resultados da pesquisa aqui levantados sublinham mudanças cruciais na forma de se conceber a velhice. A teoria das representações sociais foi-nos fundamental para compreender a complexidade desse movimento, apesar de capturado por meios de retratos circunstanciado da realidade. Por outro lado, o que nos faz compreender essas mudanças paulatinas são os estudos de décadas precedentes.

Outras pesquisas futuras poderão ir ao encontro dessa na medida em que a velhice se evidencia sob múltiplas formas de expressão desenvolvimental, inclusive propiciando releituras dessa fase do desenvolvimento humano.

As mudanças representacionais começam a partir de determinados grupos, que mesmo concebendo a velhice por meio de uma estruturação que é compartilhada por outros (LIRA, 


\section{REVISTA DE ADMINISTRAÇÃO EDUCACIONAL}

SOUZA, SILVA, 2017), o fazem espelhando sua subjetividade e condições materiais de existência.

\section{REFERÊNCIAS}

ALMEIDA, Angela Maria; CUNHA, Gleicimar Gonçalves. Representações sociais do desenvolvimento humano. Psicologia: reflexão e crítica, v. 16, n. 1, p. 147-155, set. 2003.

ARAÚJO, Ludgleydson Fernandes de; COUTINHO, Maria da Penha de Lima; CARVALHO, Virgínia Ângela Menezes de Lucena. Representações sociais da velhice entre idosos que participam de grupos de convivência. Psicologia: ciência e profissão, v. 25, n. 1. p. 118-131, mar.2005.

ARRUDA, Angela Maria Silva. Envelhecer: uma novidade? In: TURA, Luiz Fernando Rangel.; SILVA, Antonia. Oliveira. (Orgs.). Envelhecimento e Representações Sociais. Rio de Janeiro: Quartet: Faperj, 2012. p. 37-316.

CAMARGO, Brigido Vizeu. et al. Representações de felicidade. In: NERI, Anita Liberalesso.; GUARIENTO, Maria Elena (Orgs.). Fragilidade, Saúde e Bem-Estar em Idosos: dados do estudo FIBRA Campinas. Campinas: Alínia, 2011. p. 239-256.

CAMPOLINA, Alessandro Gonçalves et al. A transição de saúde e as mudanças na expectativa de vida saudável da população idosa: possíveis impactos da prevenção de doenças crônicas. Cadernos de Saúde Pública, v. 29, n. 6. p. 1217-1229, jun. 2013.

CARVALHO, José Alberto Magno de; GARCIA, Ricardo Alexandrino. O envelhecimento da populaçäo brasileira: um enfoque demográfico. Cad. saúde pública, v. 19, n. 3. p. 725-733, mai/jun.2003.

BRAZ, Márcia Cristina Dantas Leite. et al. O Procedimento de Classificações Múltiplas (PCM) e sua pertinência ao estudo das representações sociais. In: SOUSA, Clarilza Prado de.; BÔAS, Lúcia Pintor Santiso Villas; NOVAES, Adelina de Oliveira; DURAN, Marília Claret Geraes. (Orgs.) Representações Sociais: estudos metodológicos em educação. São Paulo: Fundação Carlos Chagas, 2011. (p. 53-82).

LIRA, A. A. D.; SOUZA, L. S. B. ; SILVA, E. L. . A Velhice na Visão de Estudantes Universitários de Ciências Humanas, Ciências da Saúde e Ciência \& Tecnologia da UFCG. In: SILVA, Antonia Oliveira; CAMARGO, Brígido Vizeu. (Org.). Representações sociais do envelhecimento e da saúde. 1ed.Natal: EDUFRN, 2017, v. 1, p. 177-198. 


\section{REVISTA DE ADMINISTRAÇÃO EDUCACIONAL}

LIRA, A. A. D. et al. A velhice na perspectiva do alunado do ensino médio: um estudo comparativo entre a rede pública e particular de ensino. In: LIRA, André Augusto Diniz; MIRANDA, Marly Medeiros; BRITO, Suerde Miranda de Oliveira. (Org.). Revisitando o Diálogo em Representações Sociais e Educação (E-book). Campina Grande: EDUFCG, 2016, v. 1, p. 257-284.

MAGNABOSCO-MARTINS, Claudia Regina; VIZEU-CAMARGO, Brigido; BIASUS, Felipe. Representações sociais do idoso e da velhice de diferentes faixas etárias. UniversitasPsychologica, v. 8, n. 3, abr/out. 2009.

NASCIMENTO, Mariana Costa; CALSA, Geiva Carolina. Velhice e juventude: revisão da produção acadêmica brasileira acerca de suas representações sociais (2008-2015). Educação \& Formação, Fortaleza,v. 2, n. 5. p. 131-146, maio/ago. 2017.

NERI, Anita Liberalesso. Atitudes e preconceitos em relação à velhice. In: NERI, Anita Liberalesso (Org.). Idosos no Brasil: vivências, desafios e expectativas na terceira idade. São Paulo: Perseu Abramo, SESC, 2007. p. 33-46.

NERI, Anita Liberalesso. Conceitos e teorias sobre o envelhecimento. Neuropsicologia do envelhecimento: uma Abordagem Multidimensional, p. 17-42, 2013.

NERI, Anita Liberalesso. Contribuições da psicologia ao estudo e à intervenção no campo da velhice. Revista Brasileira de Ciências do Envelhecimento Humano, v. 1, n. 1, jan/jun. 2004.

NERI, Anita Liberalesso. Envelhecer num país de jovens: significados de velho e velhice segundo brasileiros não idosos. Campinas, SP: Editorada Unicamp, 1991.

RECH WACHELKE, João Fernando et al. Princípios organizadores da representação social do envelhecimento: dados coletados via internet. Estudos de Psicologia, v. 13, n. 2, ago. 2008.

ROAZZI, Antonio. Categorização, formação de conceitos e processos de construção do mundo: procedimento de classificações múltiplas para o estudo de sistemas conceituais e sua forma de análise através de métodos multidimensionais. Cadernos de Psicologia, v.1, p. 1-27, ago/set 1995.

TURA, Luiz Fernando Rangel.; SILVA, Antonia Oliveira. (Org.) Envelhecimento $e$ representações sociais. Rio de Janeiro: FAPERJ, 2012.

SANTOS, Sueli Souza dos.; CARLOS, Sérgio Antônio. Envelhecendo com apetite pela vida: interlocuções psicossociais. Petrópolis: Vozes, 2013. 


\section{REVISTA DE ADMINISTRAÇÃO EDUCACIONAL}

SANTOS, Verônica Braga; TURA, Luiz Fernando Rangel; ARRUDA, Angela Maria Silva. As representações sociais de" pessoa velha" construídas por idosos. Saúde e sociedade, v. 22, n. 1, p. 138-147, nov. 2013.

SOUZA, Fernando Menezes Campello de; SOUZA, Bruno Campello de.; SILVA, Alexandre Stamford da. Elementos da Pesquisa Científica em Medicina: estatística e metodologia científica para profissionais de Saúde. Recife: UFPE, 2002.

VELOZ, Maria Cristina; NASCIMENTO-SCHULZE, Clélia Maria; CAMARGO VIZEU, Brígido. Representações sociais do envelhecimento. Psicologia: reflexão e crítica, v. 12, n. 2. $p$. 479-501, mar.1999.

VIEIRA, Rodrigo de Sena et al. Estereótipos sobre os idosos: dissociação entre crenças pessoais e coletivas. Temas em Psicologia, v. 23, n. 4. p. 947-958, jun/out. 2015. 